\title{
PACEMAKER MIGRATION AND SINUS NODE ARREST WITH METHOXYFLURANE AND HALOTHANE*
}

\author{
A. K. Reynolds, Ph.D., J. F. Chiz, B.SC. And A. F. PAsquet, M.D.C.M.†
}

Two of THE MOST widely used general anaesthetics, methoxyflurane (Penthrane) and halothane (Fluothane), share to some degree the same potential as many halogenated hydrocarbons - that of inducing cardiac arrhythmias when employed in conjunction with adrenergic compounds. ${ }^{1}$ The basic mechanism of this action is still poorly understood. The voluminous literature on this subject has been capably reviewed by Katz and Epstein. ${ }^{2}$ Until relatively recently, few of the studies have been carried out on single cardiac cells. We have been conducting an extensive, comparative study of the effect of these two agents on single fibers of various types of cardiac tissue. The results of the studies on pacemaker fibers are particularly interesting. ${ }^{3}$

There are conflicting reports concerning the effect of halothane on heart rate. Bradycardia has been reported by some, ${ }^{4}$ while cither no effect or acceleration has been reported by others. ${ }^{5}$ In the case of methoxyflurane, both slowing and acceleration of heart rate have been observed. ${ }^{6-9}$ Jacques and Hudon ${ }^{10}$ and Arens ${ }^{11}$ have reported cases of wandering pacemaker and nodal rhythm. In microelectrode studies on fibers of the sinoatrial node, we have shown that the slowing produced by halothane is not prevented by atropine. ${ }^{3}$ This is in agreement with the findings of Morrow and his associates in electrocardiographic studies in the intact dog. ${ }^{12}$ We also observed a biphasic effect on the spontaneous rate of sinoatrial fibers exposed to methoxyflurane. An initial brief period of acceleration always preceded the slowing. This might cxplain the cardioacceleration reported in some clinical studies. More important, perhaps, was the observation that both of these anaesthetics could cause arrest of the clectrical activity of these fibers. Complete cessation of electrical activity occurred at a time when only a modest degree of slowing had devcloped. It was associated with a progressive reduction in maximum diastolic potential, increase in the threshold potential, and loss of excitability. In the case of methoxyflurane, arrest of electrical activity was seen frequently with concentrations + as low as 0.5 per cent and consistently with 1.0 per cent. In the case of halothane, concentrations of 3 per cent or more were required. The loss of excitability was reversible and normal activity was restored after a considerable period of washing. Sinoatrial nodal fibers from cats and dogs showed the same sensitivity as those taken from rabbits.

* This investigation was supported by the Medical Research Council of Canada and the Canadian Heart Foundation.

This paper was presented in part at the Canadian Federation of Biological Sciences Meeting, Montreal, June 1970.

tDepartments of Pharmacology and Anaesthesia, Dalhousie University, Halifax, Nova Scotia, Canada.

$\$$ The term concentration used throughout this paper refers to the setting on the vaporizer.

Canad. Anaesth. Soc. J., vol. 18, no. 2, March 1971 
It was difficult to reconcile this profound effect on pacemaker fibers with the relatively few reports of loss of sinus rhythm during the course of anaesthesia with methoxyflurane. Three possible explanations suggested themselves: (1) the tissue levels of methoxyflurane achieved in our in vitro experiments are much higher for a given vaporizer setting than those realized during clinical anaesthesia, (2) nodal fibers of the three species studied are more sensitive to this agent than human nodal fibers, (3) fibers are present in the sinoatrial node which are more resistant to the action of methoxyflurane than those we had impaled with the microelectrodes. This would result in a shift in the dominant pacenaker site.

Whether or not the tissue concentrations of methoxyflurane achieved in our in vitro studies are comparable to those obtained when the anaesthetic is administered via the lungs can be established only by actual determinations of tissue levels. However, some indication of the relative concentrations may be provided by the results of electrocardiographic studies in the intact animal using the same vaporizer settings as those used in vitro. Vaporizer settings of 1.0 per cent always produced nodal rhythm in the intact animals and arrest of the sinus node in vitro. Vaporizer settings of 0.5 per cent did not produce nodal rhythm in vivo but caused arrest of the sinus node in some in vitro preparations. Based on these observations, it would appear that the tissue levels reached in vitro are somewhat higher than those attained in vivo. Since 1.0 per cent is commonly used for anaesthesia, it might be assumed that the profound effect on the isolated nodal fibers was not due to excessively high concentrations of the anaesthetic, especially since considerably higher concentrations are sometimes used for induction. In this regard, a concentration of 2.5 per cent evoked nodal rhythm within $60-90$ seconds in experimental animals. The possibility that human sinoatrial nodal fibers are much less sensitive than those of the three species used in this study is very difficult to determine. There are obvious problems in obtaining human pacemaker tissue for in vitro studies which would exhibit even relatively normal response. However, loss of sinus dominance has been reported clinically during anaesthesia with 1.0 per cent methoxyflurane. ${ }^{10,11}$

The results of the study of the third possible explanation - the presence of relatively resistant nodal fibers and a resulting shift in pacemaker site-are reported here.

\section{METHODS}

Preparations of right atria including the sinoatrial node were obtained from rabbits, cats, and dogs anaesthetized with sodium pentobarbital (Nembutal) 30 $\mathrm{mg} / \mathrm{kg}$ Iv. These were mounted in a constant temperature bath through which Tyrode solution aerated with a 95 per cent $\mathrm{O}_{2}: 5$ per cent $\mathrm{CO}_{2}$ mixture, flowed continuously at a temperature of $37^{\circ} \mathrm{C}$. Volume was maintained constant by means of a suction device. Regular atrial fibers as well as fibers of the sinoatrial nodal region were impaled under microscopic observation with conventional Ling-Gerard glass microelectrodes filled with $3 \mathrm{M} \mathrm{KCl}$. This allowed us to determine whether or not other pacemaker fibers were still active and driving the atria - after the nodal fiber originally impaled had ceased to function. Surface 
fibers only were studied. Action potentials were recorded on a Tektronix 556 oscilloscope and preserved on a Hewlett-Packard 3955 tape recorder. Permanent records were obtained by photographing the scope face either at the time of the experiment or later from the tape play-back. Halothane and methoxyflurane were introduced into the Tyrode solution in the reservoir by passing the aeration mixture through halothane and methoxyflurane vaporizers (Fluotec and Pentec Mark II). Canine Purkinje fibers were studied in a similar manner. Adrenaline was added either to the stock Tyrode solution or directly to the tissue bath according to the method of Dudel and Trautwein. ${ }^{13}$ Preparations of atria containing both the sinoatrial node and atrioventricular node were also studied.

\section{Results}

The results of ten experiments were clear cut and consistent. A typical record is shown in Figure 1. The lower action potential is from a regular atrial cell. The
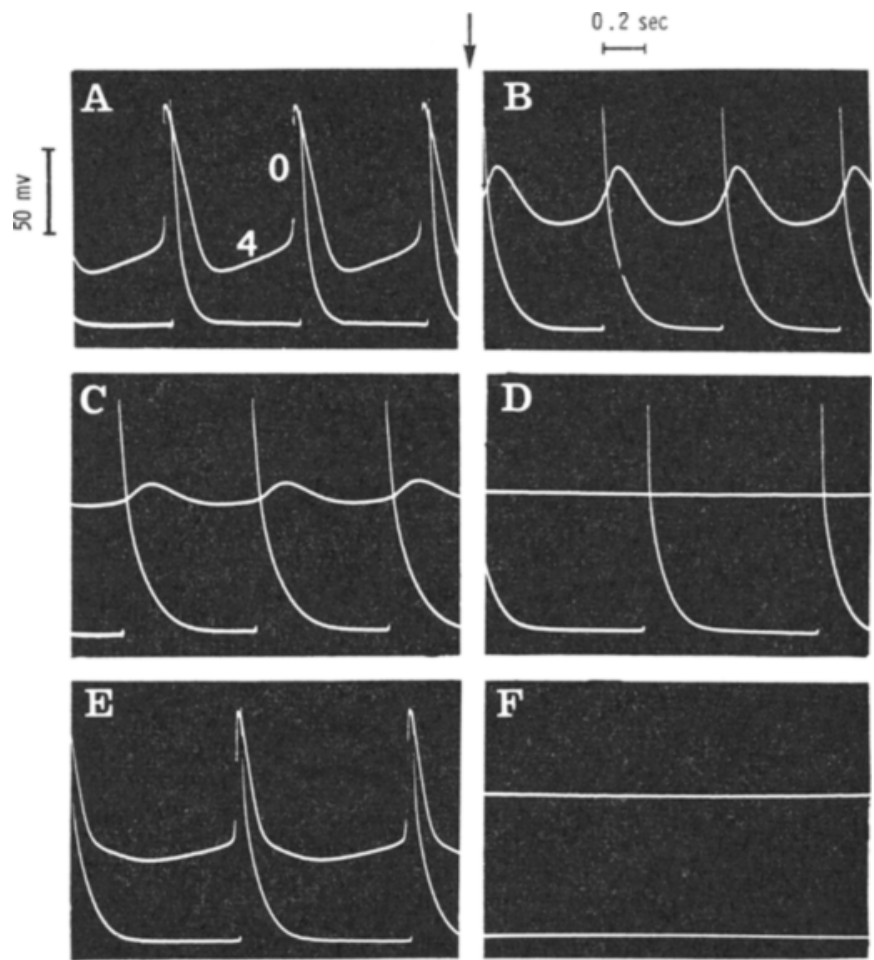

Ficune 1. The effect of methoxyflurane 1.0 per cent on the transmembrane potential of sinoatrial nodal cells. Upper trace in each record is from a nodal cell. Lower trace in each record is from a regular atrial cell. A: Control. Records B, C, and D are taken at 5-minute intervals after exposure to the anaesthetic at arrow. Record $\mathrm{E}$ is from a nodal cell that remained active after cessation of activity of cell originally impaled. Record $F$ shows the complete cessation of activity of the preparation. $0=$ phase 0 the upstroke of the action potential, $4=$ phase 4 of the action potential (slow diastolic depolarization). 
upper action potential is from a fiber in the sinoatrial nodal region. It appears to be from a true pacemaker cell, exhibiting a smooth transition from phase 4 to phase 0 - the upstroke. Even at the slow sweep speed employed, the transition is not abrupt. In addition, the temporal relationship between the two action potentials is such that the nodal fiber could indeed be the source of the impulse that is driving the atrial fiber. The records, B, C, and D are taken at 5-minute intervals following commencement of the perfusion with methoxyllurane 1.0 per cent. The most obvious effect is the depression of the nodal fiber and the virtual insensitivity of the regular atrial fiber to this concentration of the anaesthetic. In addition, by the 15-minute mark in the perfusion (record $\mathbf{D}$ ), it is quite clear that some other nodal cell is driving the atrial fiber. At this point, the electrode was removed from the nodal fiber and the area surveyed with the microelectrode in order to locate the source of the impulse that was driving the atrial fiber. In the record shown in $\mathrm{E}$, a nodal fiber that was still active has been impaled. The rather abrupt transition from phase 4 to phase 0 suggests, however, that this fiber itself is being driven by yet another nodal fiber. Actually, numerous active fibers could be found. As the perfusion continued, all nodal cells ceased to fire - usually within 30 minutes after exposure to anaesthetic. All electrical activity of the preperation was terminated and the record in $F$ shows only the resting potentials of the two impaled fibers. The ultimate effect of halothane on these preparations was identical to that of methoxyflurane, but concentrations of 3 per cent or higher were required to cause complete arrest of electrical activity. This is in excess of the concentrations normally employed for anaesthesia. In all ten preparations studied, we were able to locate active nodal fibers following cessation of activity of the
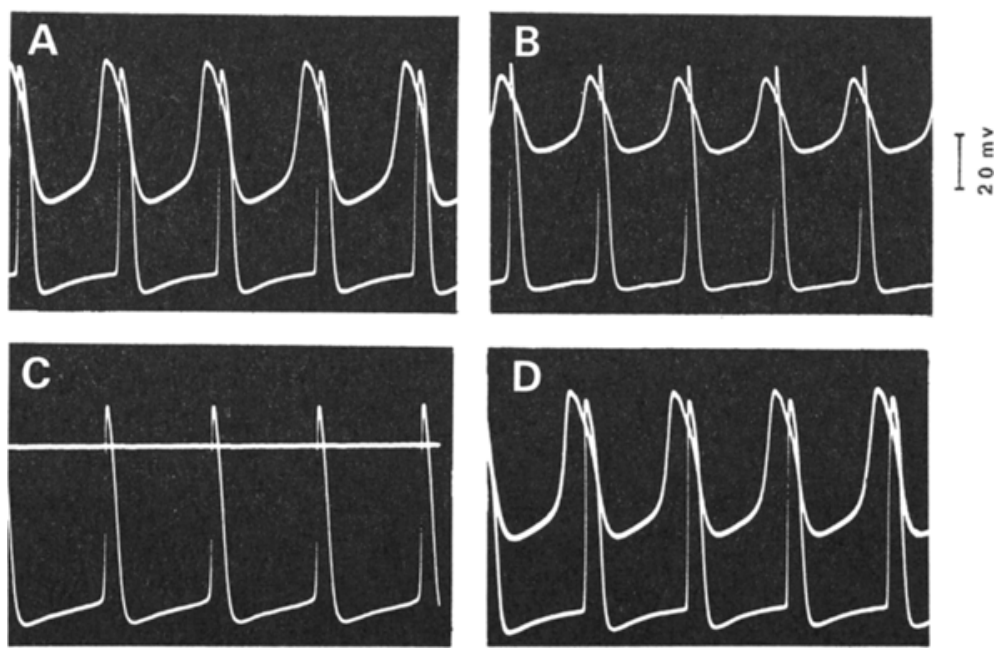

Frgure 2. The effect of methoxyturane 1.0 per cent on the transmembrane potentials of sinoatrial nodal cell (upper) and atrioventricular nodal cell (lower). A: Control. Records B and $\mathrm{C}$ are taken at 5-minute intervals following exposure to the anaesthetic. Record $D$ taken after 15 minutes washing. 

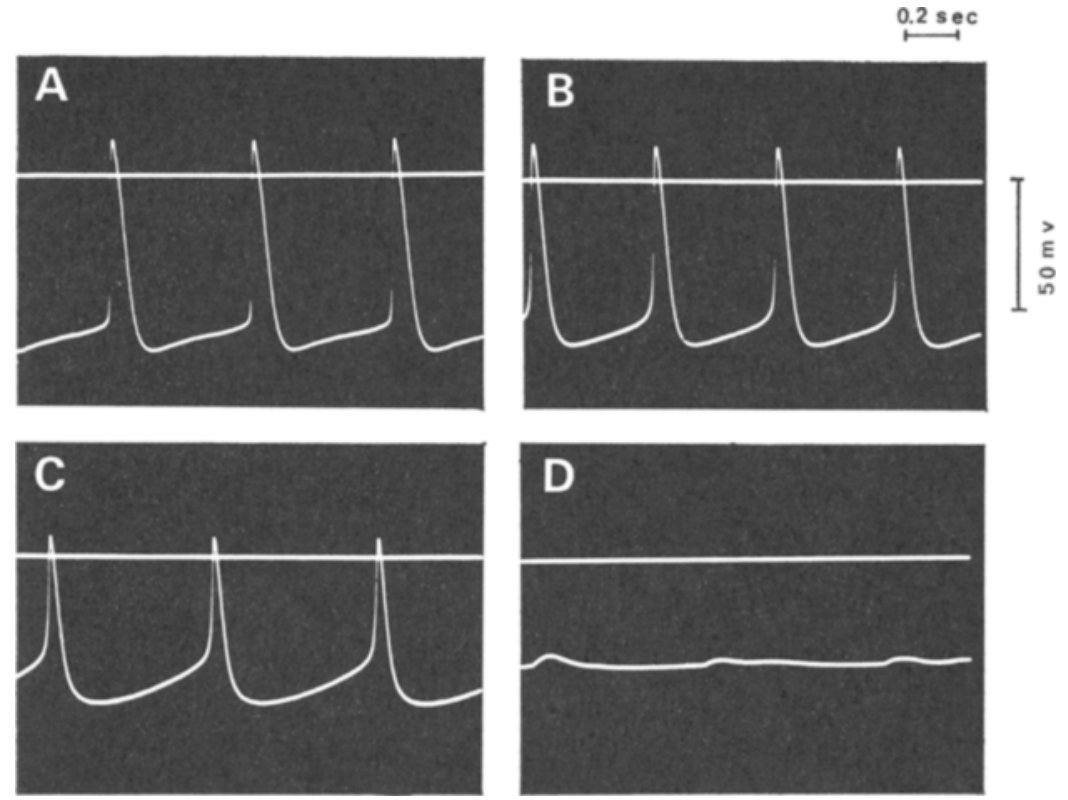

Figure 3. The effect of methoxydlurane 2.0 per cent on the transmembrane potential of an atrioventricular nodal cell. A: Control. Records $\mathbf{B}$, C, and $\mathrm{D}$ taken at 5 -minute intervals following exposure to the anaesthetic.

nodal fiber originally impaled. It is quite conceivable, of course, that the most resistant fiber might be encountered in the initial impalement.

Since nodal rhythm is evoked in experimental animals by 1 per cent methoxyflurane, we studied the effect of this concentration on the $\mathrm{A}-\mathrm{v}$ node in vitro. Preparations containing both the $\mathrm{S}-\mathrm{A}$ and $\mathrm{A}-\mathrm{V}$ nodes were exposed to 1 per cent methoxyflurane. A typical result is shown in Figure 2. The activity of the A-v node remained normal (lower record) even after complete arrest of the s-A nodal fiber (upper rccord). The action was completely reversible with washing (Figure 2D). In another series of experiments, we tested the resistance of the A-v node to higher concentrations of methoxyflurane. Figure 3 shows the effect of a concentration of 2 per cent. A biphasic action - initial brief acceleration followed by slowing and arrest - was observed just as it was in the case of the s-A node mentioned previously.

The effects of halothane and methoxyflurane on latent pacemaker fibers show one important difference. Halothane decreases the rate of spontaneous depolarization in Purkinje fibers and antagonizes the stimulant action of adrenaline on this phase of the action potential. Methoxyflurane has the opposite effect. This compound augments the rate of spontaneous depolarization and potentiates the stimulant action of adrenaline. Figure 4 shows the effect of adrenaline superimposed on the control action potential in Figure $4 \mathrm{~A}$ and the marked effect of the combination of methoxyflurane and adrenaline (upper record) in Figure 4в. This invariably resulted in the development of arrhythmias. 

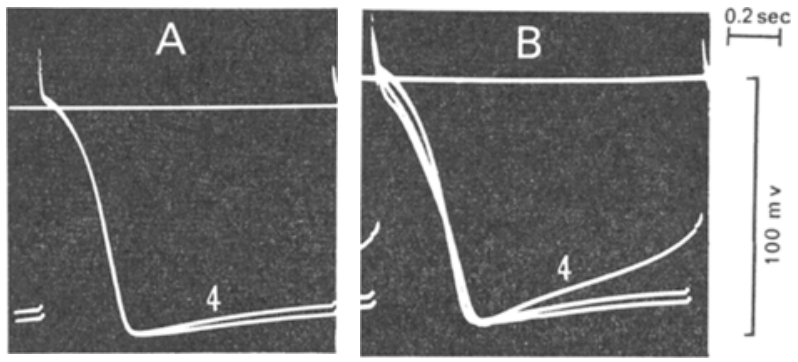

Figure 4. The effect of methoxyflurane 1.0 per cent on the transmembrane potential of a canine Purkinje fiber. A: The effect of adrenaline $10^{-6}$ (upper phase 4) superimposed on the control action potential (lower phase 4). B: The effect of adrenaline $10^{-6}$ plus methoxyflurane 1.0 per cent (upper phase 4) superimposed on record $A$. The effect of this combination on phase 4 depolarization is striking. $4=$ phase 4 of the action potential (slow diastolic depolarization).

\section{Discussion}

It is not possible to state with certainty that the nodal fiber shown in Figure $1 \mathrm{~A}$, i.e. the fiber impaled during the control period, was in fact the pacemaker fiber for the preparation. As recently emphasized by Ten Eick and Hoffman, ${ }^{14}$ this is very difficult to tell. The action potential of a fiber may have all the characteristics of a classical pacemaker fiber but not be the true pacemaker. If the nodal fiber in Figure $1_{\mathrm{A}}$ was indeed the pacemaker, then exposure to methoxyflurane which caused arrest of this fiber, resulted in a shift in the dominant pacemaker site within the node itself. The new pacemaker then maintained the activity of the atrium for some time. In any case, there are fibers present in the sinoatrial node which are more resistant than others to the depressant action of the anaesthetic. In this connection, it is interesting to note that Lu and Brooks ${ }^{15}$ have recently reported that fibers of the lower sinoatrial node are more readily stimulated by norepinephrine than are fibers of the upper node. Fibers of the lower node are more readily depressed by acetylcholine and prostigmine than fibers of the upper node. Obviously, there are two populations of nodal fibers as far as response to catecholamines and cholinergic compounds is concerned. It is not unreasonable to suppose that a similar situation may exist with respect to the response to these anaesthetic agents.

The marked effect on diastolic depolarization phase 4 of latent pacemaker fibers may induce arrythmias by two mechanisms. First, the more rapid depolarization to threshold may result in the development of ectopic foci. Second, the rate of rise of the upstroke is greatly reduced due to the lower take-off potential. This decreased rate of rise may result in decremental conduction and local areas of block - conditions which favor reentry of impulses.

From the studies reported here, it is clear that the electrical activity of sinoatrial nodal fibers of the rabbit, cat, and dog can be arrested by relatively low concentrations of methoxyflurane. Some fibers resist this effect longer than others 
but the same concentration ultimately causes arrest of all primary pacemaker fibers. A shift in the site of impulse formation to the atrioventricular node ensues. Because of the relatively small change in heart rate accompanying this shift in pacemaker site, the event could quite easily go unnoticed, if heart rate alone were being monitored. It seems quite possible that the incidence of loss of sinus dominance may actually be considerably higher than has been reported.

In the healthy myocardium, loss of sinus dominance per se may not be regarded as a serious complication. When, however, this is accompanied by a stimulation of latent pacemaker fibers in the rentricular conduction system, the gravity of the situation becomes obvious.

It is generally accepted practice to avoid the intravenous use of catecholamines during anaesthesia with these agents. Adherence to this practice would probably avoid the pronounced stimulation of latent pacemaker fibers observed with this anaesthetic-adrenergic interaction. Methoxyflurane has been finding increasingly extensive use in anaesthetic practice and its prolonged analgesic action endows it with a special attribute. We see no reason at present to condemn the use of this agent on the basis of our electrophysiological studies on cardiac tissue. We do feel, however, that attention should be drawn to the rather profound effect of this agent on pacemaker cells in experimental animals. Based on the observations of its depressant effect on primary and stimulant effect on latent pacemaker cells, we might question the wisdom of employing the high concentrations of this anaesthetic often used for induction.

\section{SuMmary}

Intracellular recording studies have been carried out on the effects of methoxyflurane (Penthrane) and halothane (Fluothane) on cardiac pacemaker fibers in the rabbit, cat, and dog. Both compounds are capable of causing arrest of electrical activity of fibers of the sinoatrial node. The concentration of halothane required is higher than that normally employed for clinical anaesthesia, but the effect is seen with methoxyflurane in concentrations as low as 0.5 per cent. The effect is reversible. Some fibers resist the action longer than others. This effect on pacemaker fibers could easily go unnoticed, if only heart rate was being monitored. In the intact animal, and in isolated preparations, it leads to a shift in pacemaker site to the $\mathrm{A}-\mathrm{V}$ node. The A-V node resists a concentration of 2 per cent methoxyflurane for some time, but cventually activity ceases. In the case of methoxyflurane, latent pacemakers are stimulated rather than depressed and this effect is quite marked in the presence of adrenaline. It is felt that the incidence of nodal rhythm during anaesthesia with this agent is probably higher than reports would indicate. We are inclined to question the wisdom of using methoxyflurane in concentrations of 2.0 per cent and higher.

\section{RÉSUMÉ}

Nous avons comparé les effets du méthoxyflurane (Penthrane) et de l'halothane (Fluothane) sur les cellules des noeuds isolés sinoauriculaire et atrioventriculaire 
en employant les techniques de microélectrodes. Les deux agents anesthésiques sont capables de causer l'arrêt de l'activité électrique et, dans le cas du méthoxyflurane, cela peut survenir avec des concentrations employées ordinairement pour l'anesthésie clinique. Cet effet entraine un déplacement du site du pacemaker dominant au noeud atrioventriculaire, lequel est quelque peu plus résistant à l'action déprimante. Les cellules de Purkinje dans le système de conduction ventriculaire sont déprimées par l'halothane mais stimulées par le méthoxyflurane. L'action stimulante est plutôt marquée si l'on associe méthoxyflurane et adrénaline. Comme résultat de ces études, nous avons l'impression que la fréquence de la perte de dominance du sinus durant l'anesthésie au méthoxyflurane est beaucoup plus élevée que les rapports semblent lindiquer. Cela peut facilement passer inaperçu si l'on se contente d'enregistrer la fréquence des pulsations. La décision d'employer des concentrations de méthoxyflurane de 2.0 pour cent et plus est d'une sagesse douteuse.

\section{ACKNOWLEDGMENTS}

The authors wish to express their sincere thanks to Dr. Leighton Smith, Medical Director, Ayerst Laboratories, Montreal, Canada and Dr. W. Ronald Porter, Medical Director, Abbott Laboratories Ltd., Montreal for most generous supplies of halothane (Fluothane, Ayerst) and methoxyflurane (Penthrane, Abbott) and for the Fluotec and Pentec vaporizers used in this study.

\section{REFERENCES}

1. Price, H. L. The significance of catecholamine release during anaesthesia. Brit. J. Anaesth. 38: 705 (1966).

2. Katz, R. L. \& Epstein, R. A. The interaction of anesthetic agents and adrenergic drugs to produce cardiac arrhythmias. Anesthesiology. 29: 763 (1968).

3. Reynolds, A. K.; Chiz, J. F; \& Pasquet, A. F. Halothane and Methoxyflurane - a comparison of their effects on cardiac pacemaker fibers. Anesthesiology. 33: 602 (1970).

4. Deutsch, S.; Linde, H. W.; Dripps, R. D.; \& Price, H. L. Circulatory and respiratory actions of halothane in normal man. Anesthesiology. 23: 631 (1962).

5. Eger, E. I.; Smith, N. T.; Stoelting, R. K.; Cullen, D. J.; Kadis, L.; \& Whitcher, C. E. Cardiovascular effects of halothane in man. Anesthesiology. 32: 396 (1970).

6. McCaffrey, F. W. \& Mate, M. J. Methoxyflurane: a report of 1200 cases. Canad. Anaesth. Soc. J. 10: 103 (1963).

7. Moffat, E. A. \& Sessler, A. D. Deep circulation in anaesthesia. Canad. Anaesth. Soc. J. 11: 173 (1964).

8. Whlker, J. A.; Eggers, W. N., Jr.; \& Allen, C. R. Cardiovascular effects of methoxyflurane anaesthesia in man. Anesthesiology. 23: 639 (1962).

9. Dobkin, A. B. \& Fedoruk, S. Comparison of the cardiovascular, respiratory and metabolic effects of methoxyflurane and halothane in dogs. Anesthesiology. 22: 355 (1961).

10. JACQues, A. \& Hudon, F. Effect of epinephrine on the human heart during methoxyflurane anaesthesia. Canad. Anaesth. Soc. J. 10:53 (1963).

11. Arens, J. F. Methoxyflurane and epinephrine administered simultaneously. Anesthesia and Analgesia - Current Res. 47: 391 (1968).

12. Monrow, D. H.; Gaffney, T. E.; \& Holman, J. E. The chronotropic and inotropic effects of halothane. Anesthesiology, 22: 915 (1961).

13. Dudel, J. \& Trautwein, W. Die Wirkung von Adrenalin auf das Ruhepotential von Myokardfasern des Vorhofs. Experientia. 12: 396 (1955).

14. Ten Eick, R. E. \& Hofrman, B. F. Chronotropic effects of cardiac glycosides in cats, dogs and rabbits. Circulation Res. xxv, 365 (1969).

15. Lu, H. \& Brooks, C. M. An analysis of factors operating at the cellular level to cause arrhythmias. Circulation. xxxvir, and xxxvir, Supp. vr, 130 (1968). 